\title{
Taxonomic Revision of the Southeast Asian Ant Genus Euprenolepis
}

\author{
JOHN S. LAPOLLA
}

Department of Biological Sciences, Towson University. 8000 York Road, Towson, Maryland 21252 USA. E-mail: jlapolla@towson.edu

\begin{abstract}
The taxonomy of Euprenolepis has been in a muddled state since it was recognized as a separate formicine ant genus. This study represents the first species-level taxonomic revision of the genus. Eight species are recognized of which six are described as new. The new species are E. echinata, E. maschwitzi, E. thrix, E. variegata, E. wittei, and E. zeta. Euprenolepis antespectans is synonymized with E. procera. Three species are excluded from the genus and transferred to Paratrechina as new combinations: P. helleri, P. steeli, and P. stigmatica. A morphologically based definition and diagnosis for the genus and an identification key to the worker caste are provided.
\end{abstract}

Key words: fungivory, Lasiini, Paratrechina, Prenolepis, Pseudolasius

\section{Introduction}

Until recently, virtually nothing was known about the biology of Euprenolepis ants. Then, in a groundbreaking study by Witte and Maschwitz (2008), it was shown that E. procera are nomadic mushroomharvesters, a previously unknown lifestyle among ants. In fact, fungivory is rare among animals in general (Witte and Maschwitz, 2008), making its discovery in Euprenolepis all the more spectacular. Whether or not this lifestyle is common to all Euprenolepis is unknown at this time (it is known from at least one other species [V. Witte, pers. comm.]), but a major impediment to the study of this fascinating behavior has been the inaccessibility of Euprenolepis taxonomy. Since being raised to full genus level by Brown (1953), there has been no taxonomic synthesis of Euprenolepis and considerable confusion as to which species actually belong within it.

Euprenolepis was constructed as a subgenus within Prenolepis by Emery (1906), but he later moved the subgenus to Paratrechina (Emery, 1925). When Euprenolepis was raised to full genus level by Brown (1953), he also synonymized Chapmanella with Euprenolepis. Work in progress (LaPolla et al., in prep) will address the phylogenetic position of Euprenolepis and its close relatives.

This study provides a morphological framework for defining and diagnosing Euprenolepis, and represents the first species-level revision of the genus.

\section{Materials and methods}

Specimens examined for this study are deposited in the following institutions:

ANIC CSIRO, Australian National Insect Collection, Canberra, Australia

BMNH Natural History Museum, London, UK

KEPC Katsuyuki Eguchi personal collection, Nagasaki, Japan

MCSN Museo Civico di Storia Naturale "Giacomo Doria", Genova, Italy

MCZC Museum of Comparative Zoology, Cambridge, MA, USA 
MHNG Muséum d' Histoire Naturelle, Geneva, Switzerland

MNHB Humboldt-Universität zu Berlin, Museum für Naturkunde, Berlin, Germany

NHMB Naturhistorisches Museum, Basel, Switzerland

SYPC Seiki Yamane personal collection, Kagoshima, Japan

USNM National Museum of Natural History, Washington, D.C., USA

All measurements were taken at various powers with a Leica MZ16 microscope using a micrometer stage with a digital readout, recorded to the nearest $0.001 \mathrm{~mm}$ and rounded to two decimal places for presentation. All measurements are given in millimeters. Digital color images were created using a Q-Imaging digital camera and Syncroscopy Auto-Montage software. All morphological terminology for measurements and indices employed throughout are found below; measurements and indices follow Bolton, 1994 and Ward, 2001, with modifications.

GL (Gaster Length): the length of the gaster in lateral view from the anteriormost point of first gastral segment (third abdominal segment) to the posteriormost point.

HL (Head Length): the length of the head proper, excluding the mandibles; measured in full-face view from the midpoint of the anterior clypeal margin to a line drawn

across the posterior margin from its highest points (to accommodate species where

the posterior margin is concave).

HW (Head Width): the maximum width of the head in full-face view (excluding the portion of the eyes that extends past the lateral margins of the head).

SL (Scape Length): the maximum length of the antennal scape excluding the condylar bulb and neck.

TL (Total Length): HL+WL+GL.

WL (Weber's Length): in lateral view, the distance from the posteriormost border of the metapleural lobe to the anteriormost border of the pronotum, excluding the neck.

CI (Cephalic Index): (HW/HL) • 100.

SI (Scape Index): (SL/HW)・100.

\section{Diagnosis of the Genus Euprenolepis Emery}

Euprenolepis Emery, 1906: 134, as subgenus of Prenolepis. Type species: Prenolepis (Euprenolepis) procera, by original description. Euprenolepis in Camponotinae, Wheeler 1910: 143; in Camponotinae, Forel, 1917: 249; as subgenus of Prenolepis, Wheeler 1922: 697; as subgenus of Paratrechina, Emery, 1925: 223; in Formicinae, Donisthorpe: 1943: 645; as subgenus of Paratrechina, Chapman and Capco, 1951: 218; raised to genus and senior synonym of Chapmanella, Brown, 1953: 6 (here maintained); in Formicinae, Wheeler and Wheeler,1985: 258; in Formicinae, Lasinii, Dlussky and Fedoseeva, 1988: 77; in Formicinae, Prenolepidini, Hölldobler and Wilson, 1990: 18; in Formicinae, Pseudolasius genus-group, Agosti, 1991: 296; in Formicinae, Lasiini, Bolton, 1994: 50; in Formicinae, Plagiolepidini, Bolton, 2003: 23, 102.

Worker (minors and majors):

1) Medium sized (measured in this study between $2.9-6.25 \mathrm{~mm}$ in total length) yellow to dark brown formicine ants.

2) E. procera known to be polymorphic with a minor and major worker castes, unclear if other species are also polymorphic.

3) Antennae 12 segmented; torulae widely separated from each other, not touching posterior clypeal margin.

4) Scapes long, always surpassing posterior margin, and with scattered erect setae.

5) Eyes generally large (one known exception E. negrosensis), near midline of head.

6) Mandibles broad with 5 teeth; basal tooth with an obtuse angle on the inner mandibular margin (one known exception E. negrosensis, where basal tooth is usually roughly quadriform relative to inner mandibular margin); apical tooth large and curved toward midline of body (fig. 1A).

7) Mandalus large and conspicuous (fig. 1A). 
8) Maxillary palps 3-segmented; labial palps 4-segmented (except in E. negrosensis which has 4 segmented maxillary palps).

9) Clypeus broad, slightly convex medially, flattening anteriorly; median clypeus without a prominent keel.

10) Anterior clypeal margin medially emarginate, with a medially placed seta.

11) Mesosoma elongate with mesothorax constricted immediately behind pronotum; propodeum high and domed-shaped.

12) Scattered erect setae across entire body.
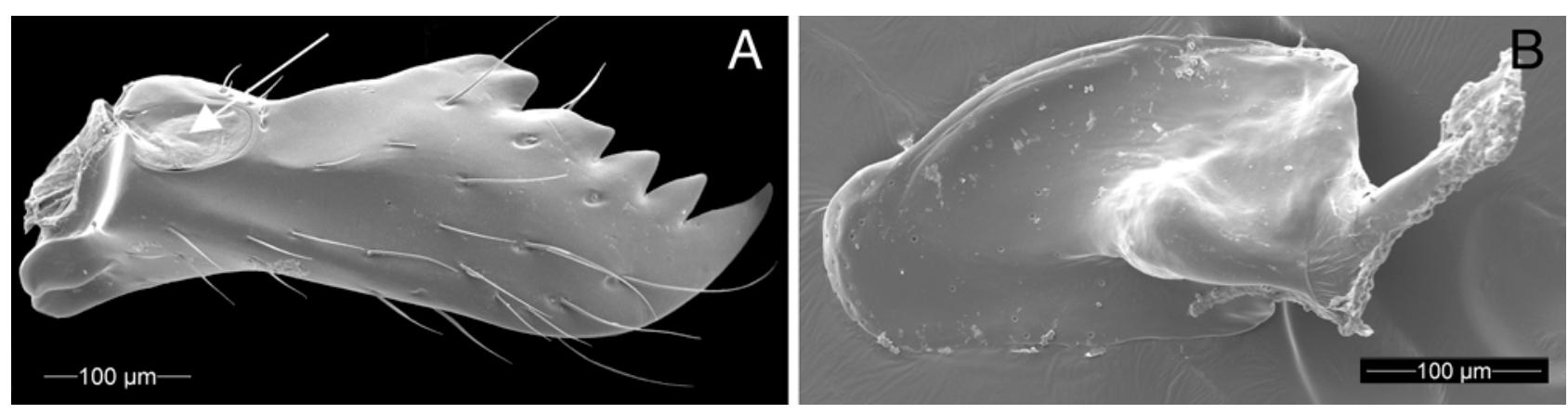

FIGURE 1. Euprenolepis procera: A) mandalus indicated by arrow (worker mandible); B) penis valve.

Queen (queens are only known from three species, E. negrosensis, E. procera, and E. wittei sp. nov., so this list must be considered provisional):

1) Generally as in worker with modifications expected for caste.

2) Eyes large; ocelli well developed and prominent.

3) Body covered in a dense layer of pubescence.

Male (males are only known from three species, E. negrosensis, E. procera, and E. wittei sp. nov., so this list must be considered provisional):

1) Eyes large, occupying more than half the lateral portion of the head; ocelli prominent.

2) Scapes long, surpassing posterior margin by at least first 3 funicular segments; 13-segmented antennae.

3) Anterior clypeal margin emarginate, as in workers; margin curls up slightly.

4) In E. procera, and E. wittei mandibles broad with only apical tooth well-developed, remainder of inner mandibular margin smooth, with a distinct basal angle. In E. negrosensis, mandibles broad, with 4 teeth; all but apical teeth are weakly developed.

5) Mesosoma modified as expected for flight muscles; propodeum indistinct.

6) In E. procera and E. wittei, penis valve apodemes terminate dorsally (fig. 1B); in lateral view, penis valves project dorsally above parameres; digiti anvil-shaped (weakly anvil-shaped in E. negrosensis), ventrally directed.

7) Digiti and cuspi meet dorsolaterally, about halfway along length of digiti.

8) Parameres and terminal gastral segments with abundant, long setae; apices of parameres bend towards the midline of the body.

\section{Discussion}

Six diagnostic characters can generally separate Euprenolepis workers from the workers of other formicine genera: 1) basal tooth with a distinct obtuse angle on the inner mandibular margin, 2) apical tooth large and curved toward midline of body, 3) mandalus large and conspicuous (fig. 1A), 4) medially clypeus without a prominent keel, 5) anterior clypeal margin medially emarginate, with a medially placed seta, and 6) widely spaced torulae. The reduced segmentation in the palps also helps in diagnosing the genus, except Pseudolasius also exhibits palpal segment reduction. With the exception of E. negrosensis, all species appear 
to have a 3:4 palpal formula. Pseudolasius typically possess 2 or 3 labial palpal segments. Euprenolepis is most likely to be confused with Pseudolasius, however, with the exception of E. negrosensis, Euprenolepis have much larger eyes than Pseudolasius species. Additionally, the six characters listed above provide a means to separate the two genera. Work in progress (LaPolla, et al., in prep) will provide a key to separate Euprenolepis from close formicine relatives.

E. negrosensis placement within the genus remains somewhat problematic, although the discovery of the males of this species does help clarify the situation (see below). The species was originally placed in its own genus, Chapmanella, by Wheeler (1930), but overall its general morphology suggest placement in Euprenolepis. However, it is distinctly unlike other species, in that it possesses very small eyes, extreme elongation of the mesosoma, a quadriform basal tooth (although rarely some specimens observed have a basal tooth as in other Euprenolepis species), and a 4:4 palpal formula. This species is at present maintained in Euprenolepis, but this result should be confirmed with molecular data once specimens become available for molecular study.

Morphological characters of E. negrosensis males do suggest placement within the genus for there are several shared characters among the three species where males are known. Among those characters shared with other Euprenolepis males are: 1) digiti weakly anvil-shaped, ventrally directed, 2) digiti and cuspi meeting dorsally, about halfway along length of digiti, and 3) apices of parameres bending towards the midline of the body. These three characters may represent diagnostic features for the genus. Another distinctive feature of all known Euprenolepis males is their hirsuteness, especially on the parameres and terminal gastral segments. The parameres can be difficult to see because of the presence of abundant, long setae. It appears E. negrosensis is a hypogaeic species based on its small eyes and yellow, thin cuticle, and this may explain the unusual appearance of the workers compared to other species within the genus.

It remains unclear how widespread polymorphism is in the genus. Polymorphism is exhibited in $E$. procera, with a minor and major worker caste clearly expressed. However, in no other known species is polymorphism observed. This may reflect collecting bias, because most species are only known from a few localities. However, at least one species, E. wittei, has been collected from long nest series and polymorphism has not been found in the workers (V. Witte, pers. comm.). It is worth pointing out that despite E. procera being by far the most commonly encountered Euprenolepis in collections, majors are still relatively uncommon. Based on the relatively minor morphological differences (other than size) observed between $E$. procera minors and majors, it would appear that even if majors are subsequently found in other species the provided key should still work for species-level identifications.

\section{Distribution of Euprenolepis}

Euprenolepis is endemic to southeastern Asia (fig. 2). Most species are presently known from Borneo only, but whether or not this reflects biological reality or collecting bias remains unclear. It is interesting to note that this distribution pattern is essentially the same as Cladomyrma, another Southeast Asian endemic formincine genus (Agosti, 1991).

\section{Synopsis of Euprenolepis species}

E. echinata, sp. nov.

E. maschwitzi, sp. nov.

E. negrosensis (Wheeler, W.M., 1930: 42)

E. procera (Emery, 1900: 699) $=E$. antespectans $($ Forel, 1913: 130), SYN. NOV.

E. thrix, sp. nov.

E. variegata, sp. nov.

E. wittei, sp. nov.

E. zeta, sp. nov. 


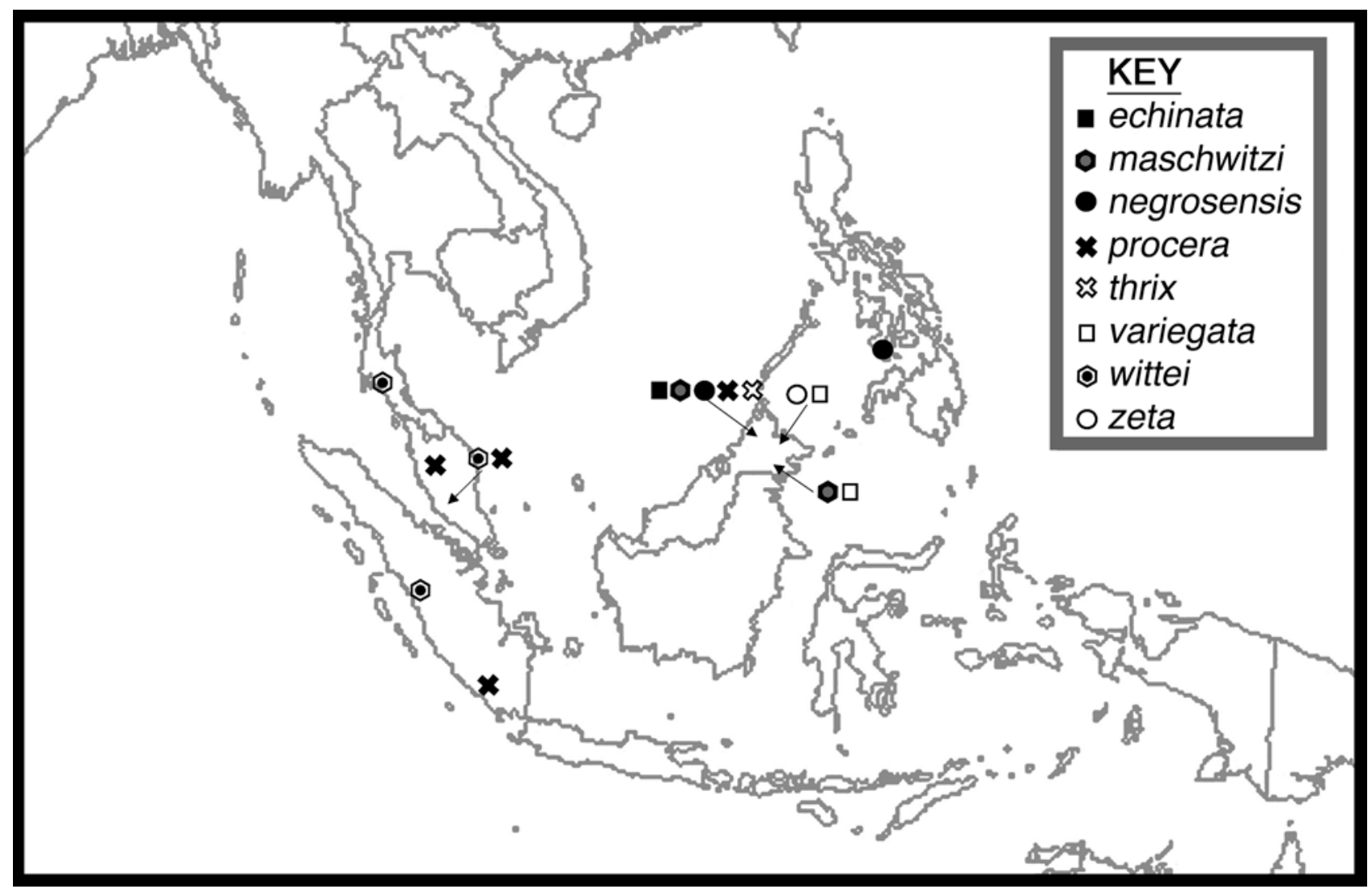

FIGURE 2. Distribution of Euprenolepis species.

\section{Names excluded from Euprenolepis}

\section{Paratrechina helleri (Viehmeyer, 1914), COMB. NOV}

Prenolepis (Euprenolepis) helleri, Viehmeyer, 1914: 41 (worker, queen and male described). Syntype workers, PAPUA NEW GUINEA [New Guinea]:

Sattelberg (MCZC; MNHG; NHMB) [7 syntype workers examined]. Emery, 1925: 224, combination in Paratrechina; Bolton, 1995: 189, combination in

Euprenolepis; Bolton et al., 2006, in Euprenolepis.

Paratrechina steeli (Forel, 1910), COMB. NOV

Prenolepis (Nylanderia) steeli, Forel, 10: 69 (worker). Syntype workers, Nauru

Island, June, 1908 (F.W. Steel) (MNHG) [2 syntype workers examined]. Emery, 1925: 224, combination in Paratrechina; Bolton, 1995: 189, combination in Euprenolepis; Bolton et al., 2006, in Euprenolepis.

Paratrechina stigmatica, (Mann, 1919), COMB. NOV

Prenolepis (Nylanderia) stigmaticus, Mann, 1919: 367. Syntype workers,

SOLOMON ISLANDS: San Cristoval, Wai-ai (USNM) [syntype worker examined]. Emery, 1925: 221, combination in Paratrechina (Nylanderia); Donisthorpe, 1941: 42, combination in Euprenolepis; Bolton, 1995: 189, in Euprenolepis; Bolton et al., 2006, in Euprenolepis. 


\section{Key to Euprenolepis workers}

(As E. procera is the only known polymorphic species, this key is designed for the minor caste. If majors are subsequently discovered for other species this key should still work, however, if appropriate adjustments for size are made to accommodate majors. For this reason I have not used measurements as a basis to distinguish between species, except where necessary to do so. Based on differences observed between E. procera majors and minors it appears as if most basic worker level diagnostic characters are retained in both castes). The funiculus is here defined as the part of the antennae minus the scape and condylar bulb and neck.

1 Scapes very long, surpassing posterior margin by about length of the entire funiculus (SI greater than 200); eyes highly reduced (EL no more than $0.05 \mathrm{~mm}$ ); pronotum and mesonotum greatly elongated, with pronotal width about the same as mesonotal width.

negrosensis

- Scapes long, but surpassing posterior margin by much less than length of the entire funiculus (SI less than 200); eyes not reduced (EL greater than $0.1 \mathrm{~mm}$ ); pronotum and mesonotum, if elongated, with pronotal width greater than mesonotal width.....

2 Head, mesosoma, and gaster dark-brown; head and mesosomal dorsum covered with a dense network of reticulate rugulae.

- Head, mesosoma, and gaster brown to yellow; head and mesosomal dorsum not covered with dense network of reticulate rugulae

3 Gastral dorsum with a layer of pubescence underneath erect setae ................................................................. 4

- Gastral dorsum without a layer of pubescence underneath erect setae.............................................................. 5

4 Gastral dorsum with a dense layer of pubsecence found on segments 1-3 (fig. 10B); from dorsum pubescence extends lateroventrally thrix

- Gastral dorsum with a scattered layer of pubescence found predominantly on segment 1 (fig. 14B); pubescence does not extend lateroventrally zeta

5 Scapes without pubescence; $2^{\text {nd }}$ gastral tergite with two distinct rows of four erect setae (8 long erect setae present on $2^{\text {nd }}$ gastral tergite); eyes more rounded in shape and notably convex in full frontal view; overall dull yellow in color

echinata

- $\quad$ Scapes with pubescence; $2^{\text {nd }}$ gastral tergite with more than 8 long erect setae and these not arranged in distinct rows; eyes more oval in shape and more flattened in appearance in full frontal view; overall shiny brown to yellow in color

6 In profile, pronotal margin linear as it rises towards mesonotum (fig. 4A); gaster yellow maschwitzi

- In profile, pronotal margin rounded as it rises towards mesonotum (figs. 11A and 12A); gaster brown to yellowishbrown ...

7 Gastral setae longer (compare to fig. 11B); majority of gastral setae greater than $0.1 \mathrm{~mm}$ in length, with longest setae greater than $0.13 \mathrm{~mm}$ in length; overall brownish-yellow, with mesosoma lighter than head and gaster ...... variegata

- Gastral setae shorter (compare to fig. 12B); majority of gastral setae less than $0.05 \mathrm{~mm}$ in length, with longest setae not exceeding $0.1 \mathrm{~mm}$ in length; overall brownish, with pronotum same color as head and gaster, with the propodeum lighter in color wittei

\section{Species accounts}

\section{Euprenolepis echinata, sp. nov.} (Figures 3A-D)

Holotype worker, MALAYSIA: Borneo, Sabah, Poring Hot Spring, East Ridge, N 0602' E 116²4', 600 m, 2.iv.1996 (A. Malsch) (USNM); paratype worker, same locality as holotype (ANIC).

Worker. Measurements ( $\mathrm{n}=1$ ): TL: 3.11; HW: 0.68; HL: 0.77; SL: 1.1; WL: 1.2; GL: 1.14. Indices: CI: 89; SI: 161.

Head brownish-yellow, with lighter mandibles and funiculi; head longer than broad. Cuticular surface dull and weakly rugoreticulate, with scattered distinctly thick erect setae, no pubescence underneath. Posterior margin complete. Eyes notably convex and more round in shape than observed in other Euprenolepis. Scapes surpass posterior margin by about length of the first four funicular segments; with scattered erect setae and no pubescence underneath. Mesosoma brownish-yellow, dull, legs slightly lighter. Pronotum elongate, very gently rises towards mesonotum (less than $30^{\circ}$ angle); mesonotum and metanotal area flat; propodeum dorsum 

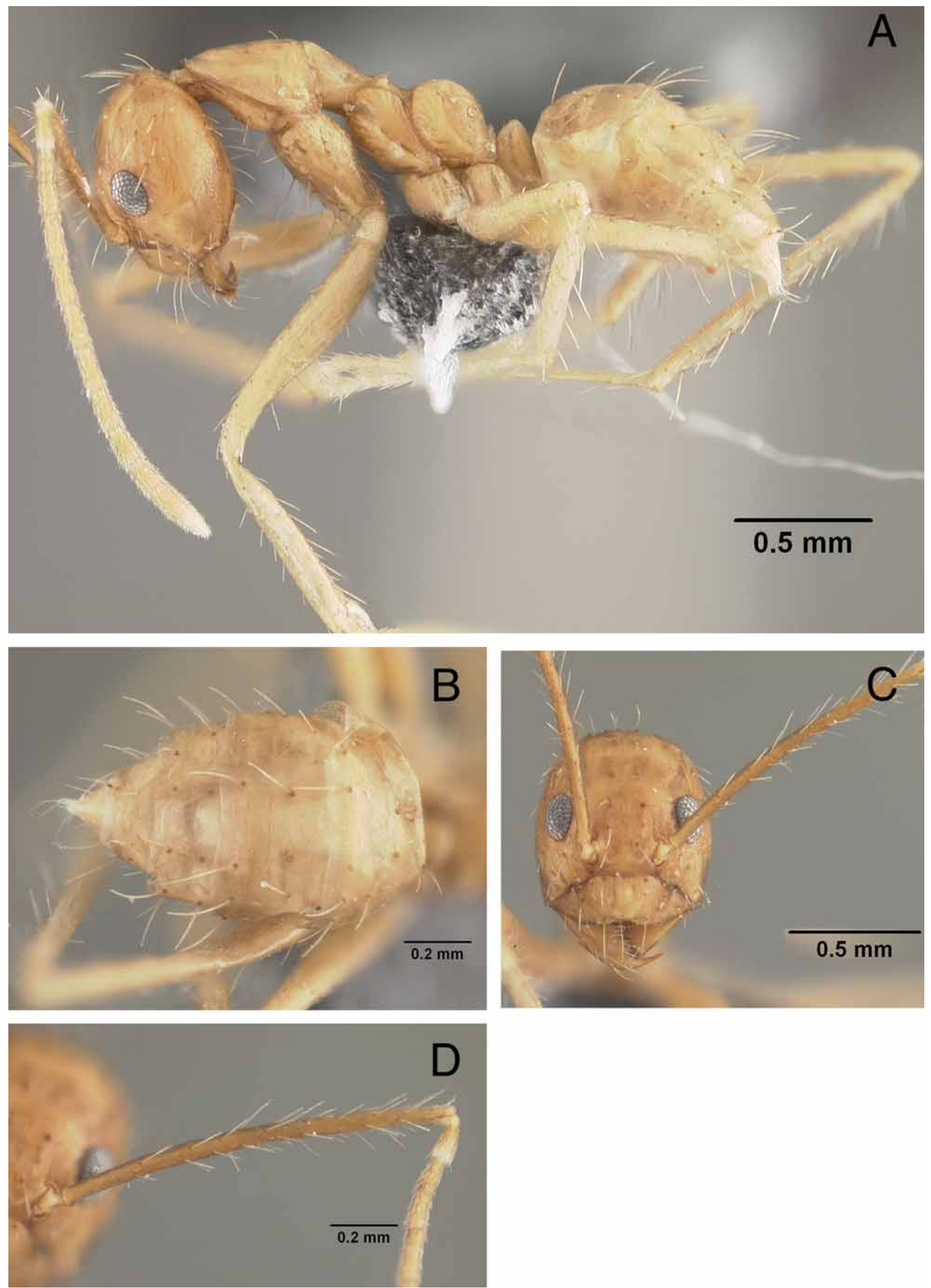

FIGURE 3A-D. E. echinata worker. A) lateral view; B) gaster in dorsal view; C) head in full-frontal view; D) scape. Holotype, Malaysia, Borneo (USNM). 
rounded, dome-like; declivity steep. Only a few erect setae present on notum, concentrated on posterior pronotum and anterior mesonotum. Petiole triangular with posterior face longer than anterior face. Gaster brownish-yellow with scattered long, erect setae and no pubescence underneath; cuticular surface dull and faintly rugoreticulate.

Etymology: The species epithet is Latin for hedgehog, in reference to the unique setae of this species.

Discussion: This is an easily recognized species with distinctly long and thick erect setae scattered across its entire body. The setal bases are especially noteworthy because they are clearly defined: large and darker than the surrounding cuticle. The pronotum is lower in profile and more elongated than is seen in other species except E. negrosensis. While the presence of long erect setae and an elongated pronotum might indicate a close relationship with E. negrosensis, it is worth noting that the erect setae are different between the two species with E. negrosensis possessing setae that are much thinner than in E. echinata.

\section{Euprenolepis maschwitzi, sp. nov.}

(Figures 4A-D)

Holotype worker, MALAYSIA: Borneo, Sabah, Poring Hot Spring, East Ridge, N 0602' E 116 $42^{\circ}, 980$ m, 31.v.1997 (A. Malsch) (USNM); 2 paratype workers, same locality as holotype (USNM; ANIC); 1 paratype worker, MALAYSIA: Borneo, Sabah, Tawau Nat. Park, N 04²3.8', E 11753.5, 13.iii.2001 (M. Pfeiffer) (USNM).

Worker. Measurements (n=3): TL: 3.41-4.02; HW: 0.84-0.89; HL: 0.84-0.93; SL: 1.03-1.14; WL: 1.21-1.36; GL: 1.32-1.73. Indices: CI: 96-100; SI: 116-125.

Head yellowish-brown, with lighter mandibles and funiculi; head about as long as broad. Cuticular surface shiny, weakly rugoreticulate, with scattered erect setae and sparse, scattered pubescence. Posterior margin complete. Scapes surpass posterior margin by about length of the first three funicular segments. Scapes with erect setae and a layer of pubescence, becoming denser distally. Mesosoma brownish-yellow, smooth and slightly dull, legs lighter, especially tarsi. Scattered erect setae of varying length concentrated on posterior pronotum and anterior mesonotum. Pronotum rises gently towards mesonotum (about $30^{\circ}$ angle). Propodeum dorsum rounded, dome-like; declivity short, but steep. Petiole triangular, inclined forward, with posterior face longer than anterior face; gaster yellowish-brown with scattered erect setae and no pubescence underneath; cuticular surface slightly dull and weakly rugoreticulate.

Etymology: The species epithet is given to honor Ulrich Maschwitz for his insightful contributions to Euprenolepis natural history.

Discussion: This species is most likely to be confused with E. variegata and E. wittei. It can be separated most easily from $E$. wittei by the scapes, which on $E$. wittei possess a thick layer of pubescence distally, and by a flatter, more elongated pronotum. Its separation from $E$. variegata can be more difficult, but $E$. variegata possesses longer gastral setae overall (majority of setae greater than $0.1 \mathrm{~mm}$ in length). Also, E. maschwitzi is lighter in color, being more yellow than either E. variegata or E. wittei, and this species possesses a duller cuticle, especially on the head and gaster.

Euprenolepis negrosensis (Wheeler, W.M., 1930)

(Figures 5A-D [worker];6A-I [queen and male] )

Chapmanella negrosensis Wheeler, W.M., 1930: 42 (worker). Holotype worker,

PHILIPPINES: Dumaguete Negros Oriental, 7 April 1927 (J.W. Chapman) (MCZC) [examined]. Brown, 1953: 6, combination in Euprenolepis; Baltazar, 1966: 267, in Euprenolepis; Bolton, 1995:189, in Euprenolepis; Bolton et al., 2006, in Euprenolepis.

Worker. Measurements (n=1): TL: 4.10; HW: 0.79; HL: 0.96; SL: 2.05; WL: 1.77; GL: 1.37. Indices: CI: 82; SI: 259 . 

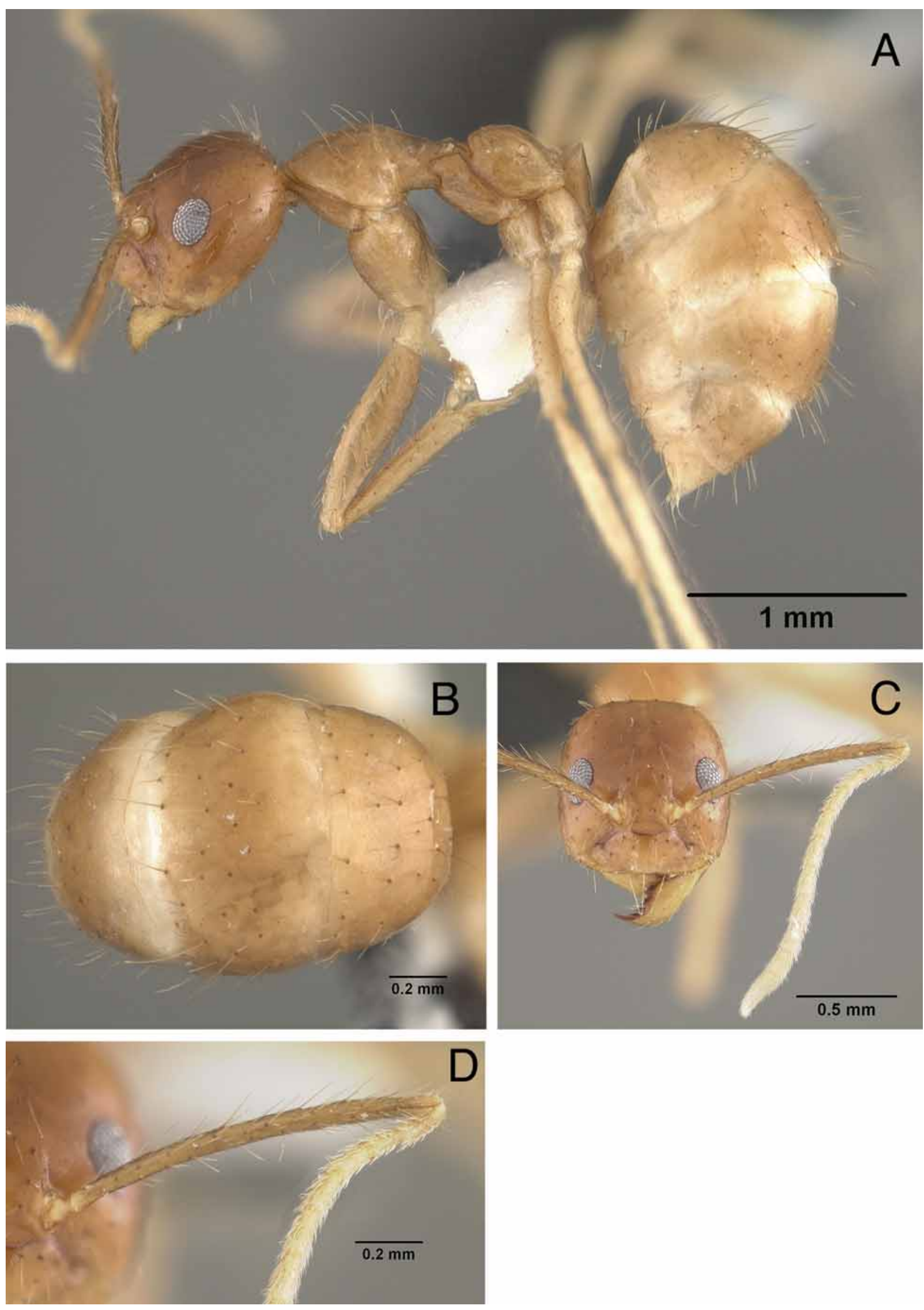

FIGURE 4A-D. E. maschwitzi worker. A) lateral view; B) gaster in dorsal view; C) head in full-frontal view; D) scape. Holotype, Malaysia, Borneo (USNM). 

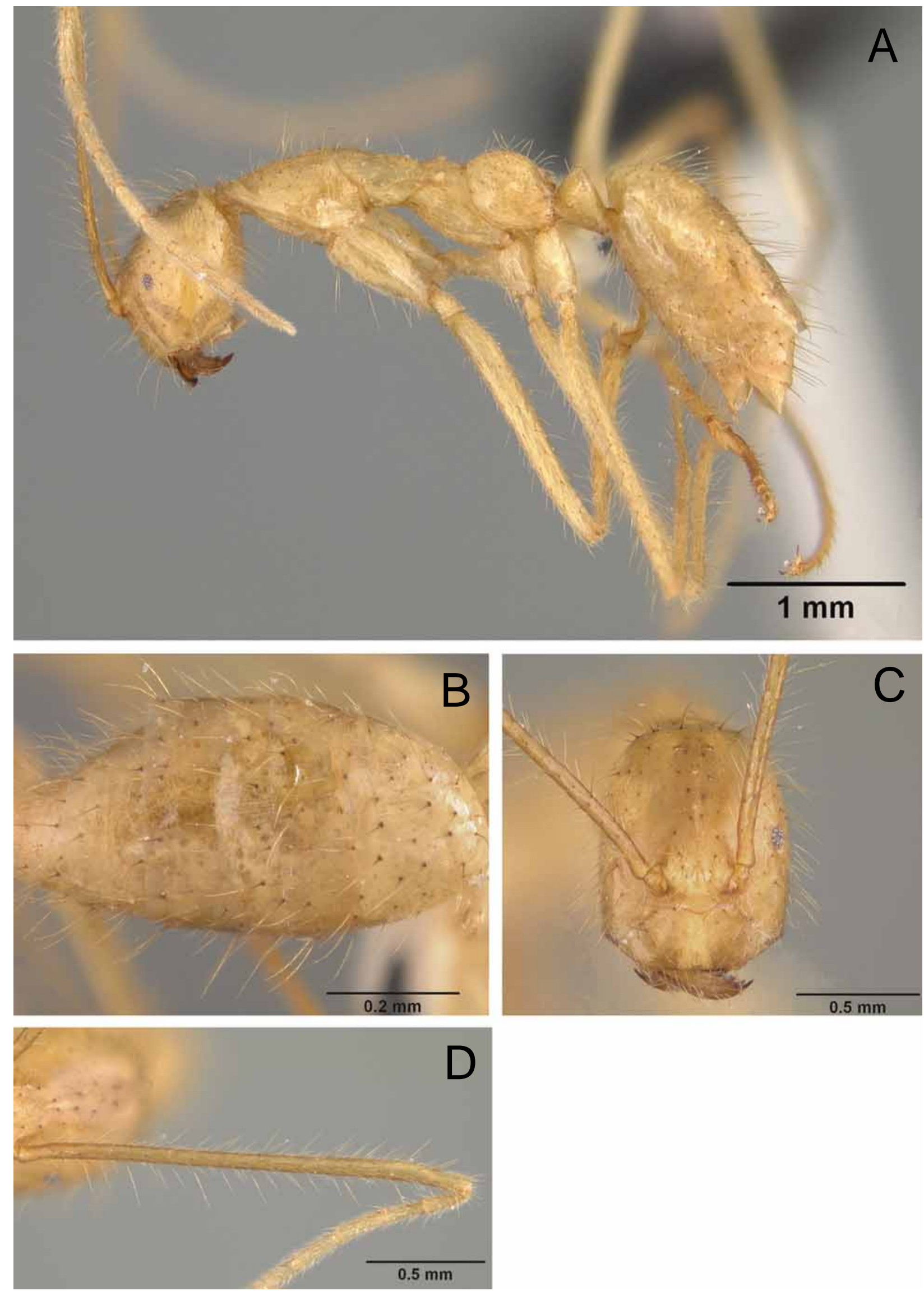

FIGURE 5A-D. E. negrosensis worker. A) lateral view; B) gaster in dorsal view; C) head in full-frontal view; D) scape. Malaysia, Borneo (SYPC). 
Head brownish-yellow, with mandibles slightly darker; head much longer than broad. Head becomes slightly wider anteriorly. Head with abundant, long, thin erect setae, only sparse pubescence. Eyes very small, medially placed. Scapes exceptionally long, surpassing posterior margin by about the length of the funiculi; covered in abundant long, thin erect setae of varying lengths, with scattered pubescence. Mandibles similar to other Euprenolepis, but basal tooth is roughly quadriform relative to inner mandibular margin; masticatory margin with two small cuspids (one specimen, however, observed with an obtuse angle to the basal tooth as seen in other Euprenolepis). Mesosoma brownish-yellow, shiny, with legs the same color. Pronotum elongate and low as it rises toward mesonotum; mesosomal dorsum with many scattered thin, erect setae of various lengths. Mesosomal dorsum at about the same height across length except toward anterior pronotum and propodeum; mesonotal area elongated. Propodeum dorsally rounded with steep, but short declivity; propodeum dorsum with abundant thin, erect setae of various lengths. Procoxae especially elongated and thin. Petiole triangular, low, not higher than propodeum in lateral view; posterior face longer than anterior face; gaster brownish-yellow with thin, long erect setae and no pubescence underneath.

Queen. Measurements (n=1): TL: 8.7; HW: 1.2; HL: 1.3; SL: 2.3; WL: 2.8; GL: 4.6. Indices: CI: 95; SI: 184.

As in worker, with modifications expected for caste and the following differences: Overall color darker than in worker, with head and gastral dorsum brown. Entire body covered in a dense layer of pubescence; erect setae of varying lengths cover head, mesosoma notum, legs and gaster.

Male. Measurements (n=1): TL: 4.4; HW: 0.9; HL: 0.9; SL: 1.6; WL: 1.7; GL: 1.8. Indices: CI: 100; SI: 176.

Overall color brown to brownish-yellow, lighter brown on legs and funiculi; head darker than remainder of body; head about as long as broad. Cuticular surface dull, covered in a dense layer of appressed setae. Eyes large and bulging beyond head outline in full-frontal view; three prominent ocelli present. Scapes very long; scapes with many erect setae of varying length and a dense layer of pubescence. Clypeus roughly rectangular, with anterior margin emarginated. Mandible broad, with 4 teeth; all but apical tooth are weakly developed; apical tooth distinct, curves in toward body midline. Mesosoma enlarged to accommodate flight muscles; covered in a layer of appressed setae, with erect setae of varying lengths dorsally and on legs. Pronotum small and distinctly collar-like; mesonotum offset from pronotum at sulcus; mesonotum rises sharply above height of pronotum, giving pronotum a shelf-like appearance in lateral view. Mesonotum flat dorsally with many erect setae of varying lengths; propodeum indistinct from remainder of mesosoma, but with steep declivity. Petiole short, triangular, upright, with posterior face only slightly longer than anterior face. Gaster with a dense layer of pubescence and erect setae; terminalia especially setose. Parameres roughly triangular, turning slightly mesad posteriorly; long setae extend off of parameres. Cuspi small and tubular, reaching digiti dorsally; digiti weakly anvil-shaped, with poorly developed point directed ventrally. Volsellar lobes flat, slightly indented relative to digital margin; appressed setae cover surface.

Additional material examined: MALAYSIA: Borneo, Sabah, Mauhua Waterfall area, ca. $1000 \mathrm{~m}$ alt., 4.xi.2000 (K. Eguchi).

Discussion: This species is easily distinguished from other species and is by far the most morphologically peculiar species in the genus. It has exceedingly long scapes, and an incredibly elongated, narrow body. Brown (1953) transferred this species to Euprenolepis based on the constriction of the mesosoma immediately behind the pronotum and the short labial and maxillary palps. As discussed under the genus diagnosis section, however, this placement remains problematic. To my knowledge this species has only been collected three times, and what is really needed are specimens that can be utilized for molecular analysis to confirm placement within Euprenolepis. Euprenolepis echinata has a similarly shaped pronotum and this may indicate a close relationship with E. negrosensis. Also as in E. negrosensis, E. echinata possesses particularly long erect setae, especially on the gaster. 

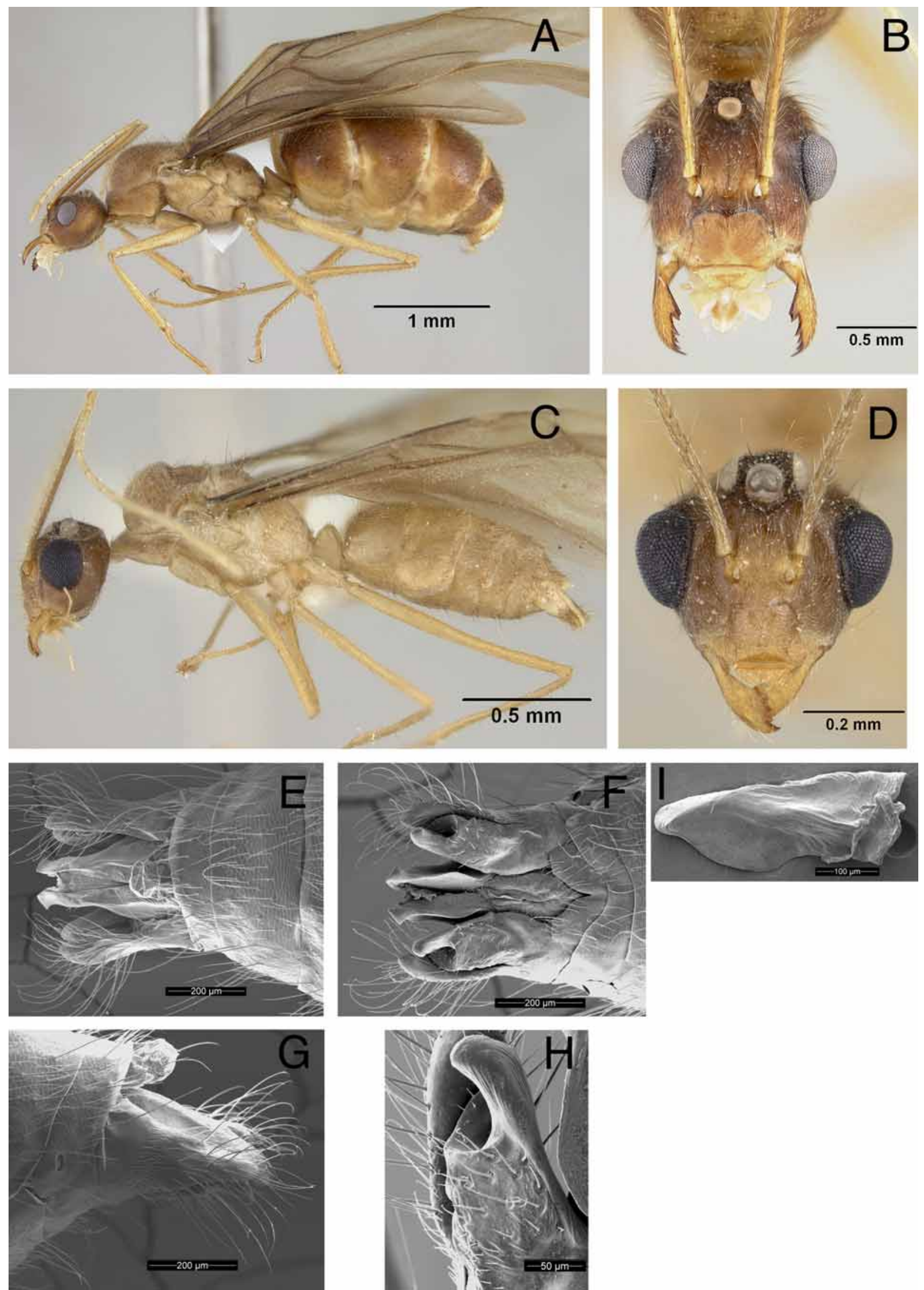

FIGURE 6A-I. E. negrosensis queen and male. A) queen in lateral view; B) queen head in full-frontal view; C) male in lateral view; D) male head in full-frontal view; E-I male genitalia: E) dorsal view; F) ventral view; G) lateral view; H) volsellar lobe; I) penis valve. Malaysia, Borneo (KEPC). 


\section{Euprenolepis procera (Emery, 1900)}

(Figures 7A-D [major]; 8A-B [minor]; 9A-I [queen and male])

Prenolepis procera Emery, 1900: 699 (worker - major and minor). Syntype workers, INDONESIA: Sumatra, Si Rembé, Panherang Pisang. (type depository unknown, not in MCSN) [not examined]. Emery, 1906: 134, combination in Prenolepis (Euprenolepis); Emery, 1925: 224, combination in Paratrechina (Euprenolepis); Bolton, 1995:189, combination in Euprenolepis; Bolton et al., 2006, in Euprenolepis.

Camponotus (Myrmocsphincta) antespectans Forel, 1913: 130 (worker). Holotype worker, INDONESIA: Sumatra (v. Buttel) (MNHB) [examined]. Emery, 1925: 223, combination in Paratrechina (Euprenolepis); Bolton, 1995:189, combination in Euprenolepis; Bolton et al., 2006, in Euprenolepis. SYN. NOV.

Worker. Measurements: Majors (n=4): TL: 5.08-6.25; HW: 1.35-1.61; HL: 1.43-1.62; SL: 1.8-2.03; WL: 1.9-2.22; GL: 1.75-2.41. Indices: CI: 94-101; SI: 126-139.

Minors (n=7): TL: 3.53-4.39; HW: 0.82-1.05; HL: 0.94-1.14; SL: 1.4-1.67; WL: 1.49-1.67; GL: 1.1-1.57. Indices: CI: 87-95; SI: 153-178.

Major. Head dark reddish-brown, roughly heart-shaped; head distinctly broader than long. Antennal funiculi slightly lighter in color. Head with scattered erect setae and a sparse layer of pubescence; cuticular surface strongly rugoreticulate. Posterior margin strongly emarginate medially. Scapes surpass posterior margin by about length of first three funicular segments; scapes with erect setae and sparse pubescence. Anterior clypeal margin strongly emarginate. Mesosoma dark reddish-brown, legs becoming lighter distally; cuticular surface rugoreticulate. Mesosomal dorsum with scattered erect setae of varying lengths on the posterior pronotum and mesonotum; sparse pubescence scattered across mesosoma, with denser patches on the anterior pronotum, metanotal area and propodeum. Pronotum rises at about $45^{\circ}$ toward mesonotum; mesonotum and mesonotal area flat; propodeum dorsum rounded, dome-like; declivity steep. Petiole triangular with posterior face longer than anterior face; gaster dark reddish-brown, covered in erect setae with a layer of pubescence; cuticular surface rugoreticulate.

Minor. As in major, with modifications expected for caste. Scapes long, surpassing posterior margin by about length of the first four funicular segments. The legs of minor workers are slightly lighter than found in majors.

Queen. Measurements (n=1): TL: 6.3; HW: 1.1; HL: 1.0; SL: 1.6; WL: 2.5; GL: 2.8. Indices: CI: 110; SI: 145.

As in worker, with modifications expected for caste and the following differences: Overall color similar to worker castes, but mottled dark brown, with lighter brown patches especially on head and mesosoma. Entire body covered in a dense layer of pubescence; short erect setae cover head, mesosoma notum, legs and gaster. Erect setae most abundant on gaster, becoming denser posteriorly.

Male. Measurements (n=2): TL: 4.54-4.85; HW: 0.70-0.75; HL: 0.86-0.89; SL: 1.54-1.63; WL: 1.77-1.81; GL: 1.88-2.18. Indices: CI: 81-84; SI: 218-219.

Overall color brown to brownish-yellow, lighter brown on legs and funiculi; head longer than broad. Cuticular surface shiny, covered in a dense layer of pubescence. Scapes long, surpassing posterior margin by about length of first four funicular segments; scapes with scattered erect setae and a dense layer of pubescence. Clypeus broad, with anterior margin emarginated. Mandible with a basal angle and a distinct apical tooth that curves in toward body midline. Mesosoma enlarged to accommodate flight muscles; covered in a layer of pubescence, with erect setae dorsally and on legs. Pronotum small and distinctly collar-like; mesonotum offset from pronotum at sulcus; mesonotum rises sharply above height of pronotum, giving pronotum a shelf-like appearance in lateral view. Mesonotum flat dorsally with scattered erect setae; propodeum indistinct from remainder of mesosoma, with declivity shallow, gently sloping toward petiole. Petiole triangular, upright, with posterior face only slightly longer than anterior face. Gaster with a dense layer of pubescence and scattered erect setae, becoming denser posteriorly toward terminalia; terminalia especially setose. Parameres roughly triangular, turning slightly mesad posteriorly; long setae extend off of parameres. Cuspi small and tubular, reaching digiti dorsally; digiti anvil-shaped, directed ventrally; digiti visible in lateral 

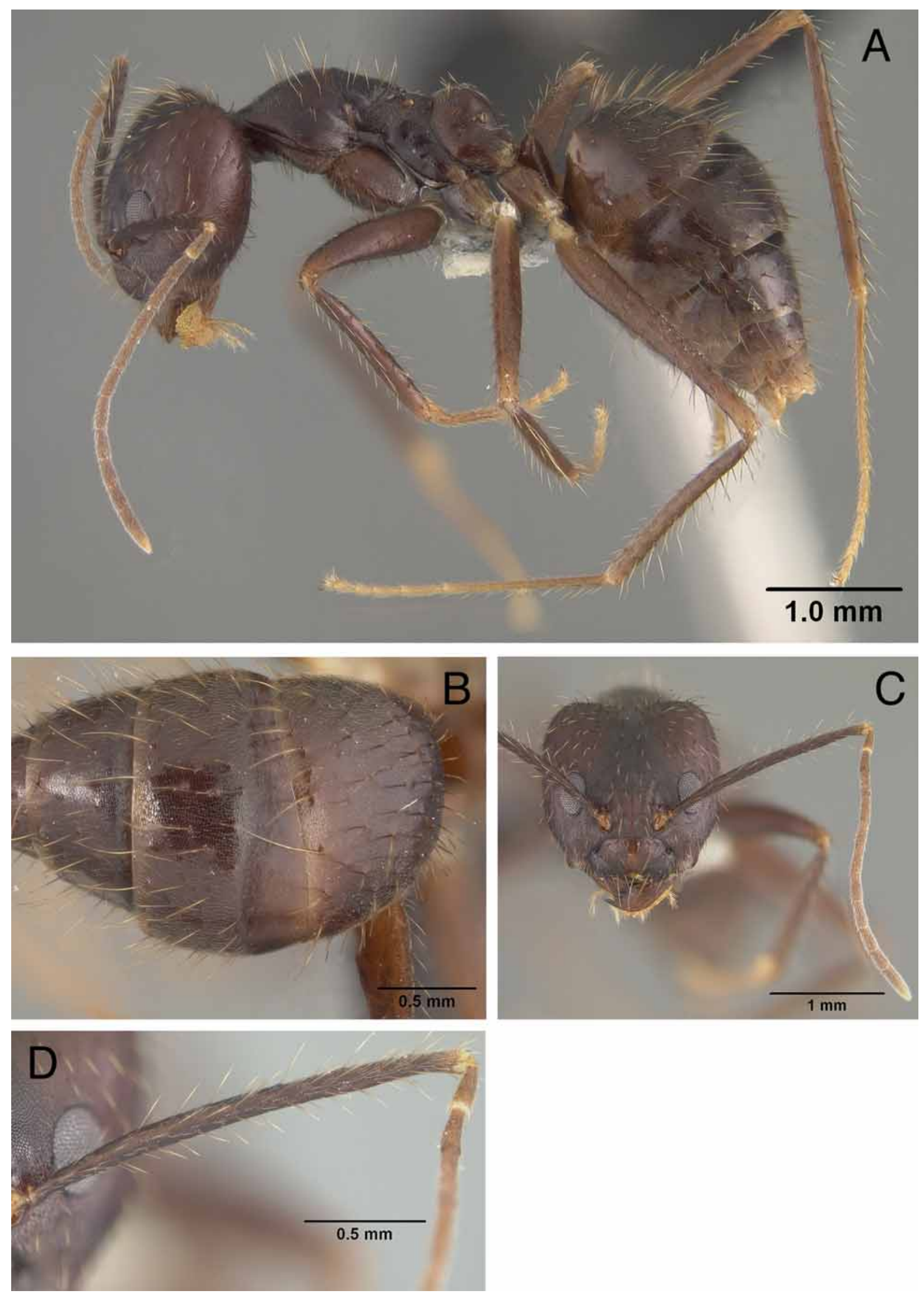

FIGURE 7A-D. E. procera major worker. A) lateral view; B) gaster in dorsal view; C) head in full-frontal view; D) scape. Malaysia, Sarawak (BMNH) 

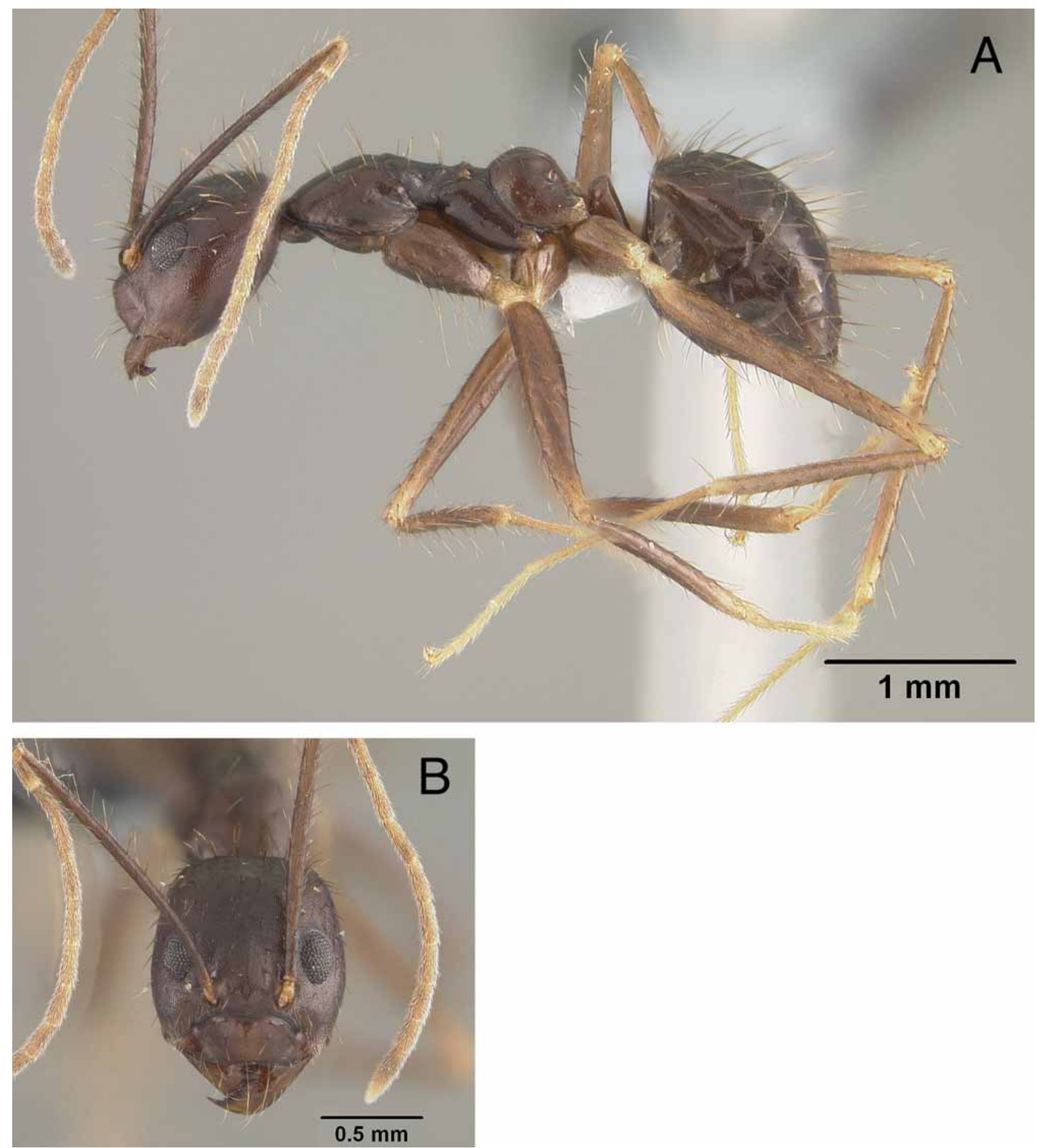

FIGURE 8A-D. E. procera minor worker. A) lateral view; B) head in full-frontal view. Malaysia (SYPC)

view. Volsellar lobes with large bulbous extensions; appressed setae cover surface. Penis valves with apodeme projecting dorsally; in lateral view the valves extend dorsally.

Additional material examined: INDONESIA: South Sumatra, Lampung, Wai Lima 12.xi.1921(Karny); Sumatra, Prov. Lampung, Sumberaja, 4 59' 30" S, 104 31' 30" E, 735 m, 15-30.i.2004 (F. Susilo); MALAYSIA: Kinabalu Nat. Park, Poring Hot Spring, East Ridge, 11.07.-20.07.1995 (C. Brühl); Sarawak, $4^{\text {th }}$ Div. G. Mulu Nat. Park, 14.x.1977 (B. Bolton); Neg. Sembilian, Pasoh Forest Reserve, xi.1994 (M. Brendell et al.); Pinang-Pinang, Ulu Gadut, Padang, 11.ii.2004 (S. Yamane); Perak, Trolac Forest Res., 6.vii.1967 (R. Crozier); Selangor, Ulu Gombak For. Reserve, 24.vii.1967 (R. Crozier). 

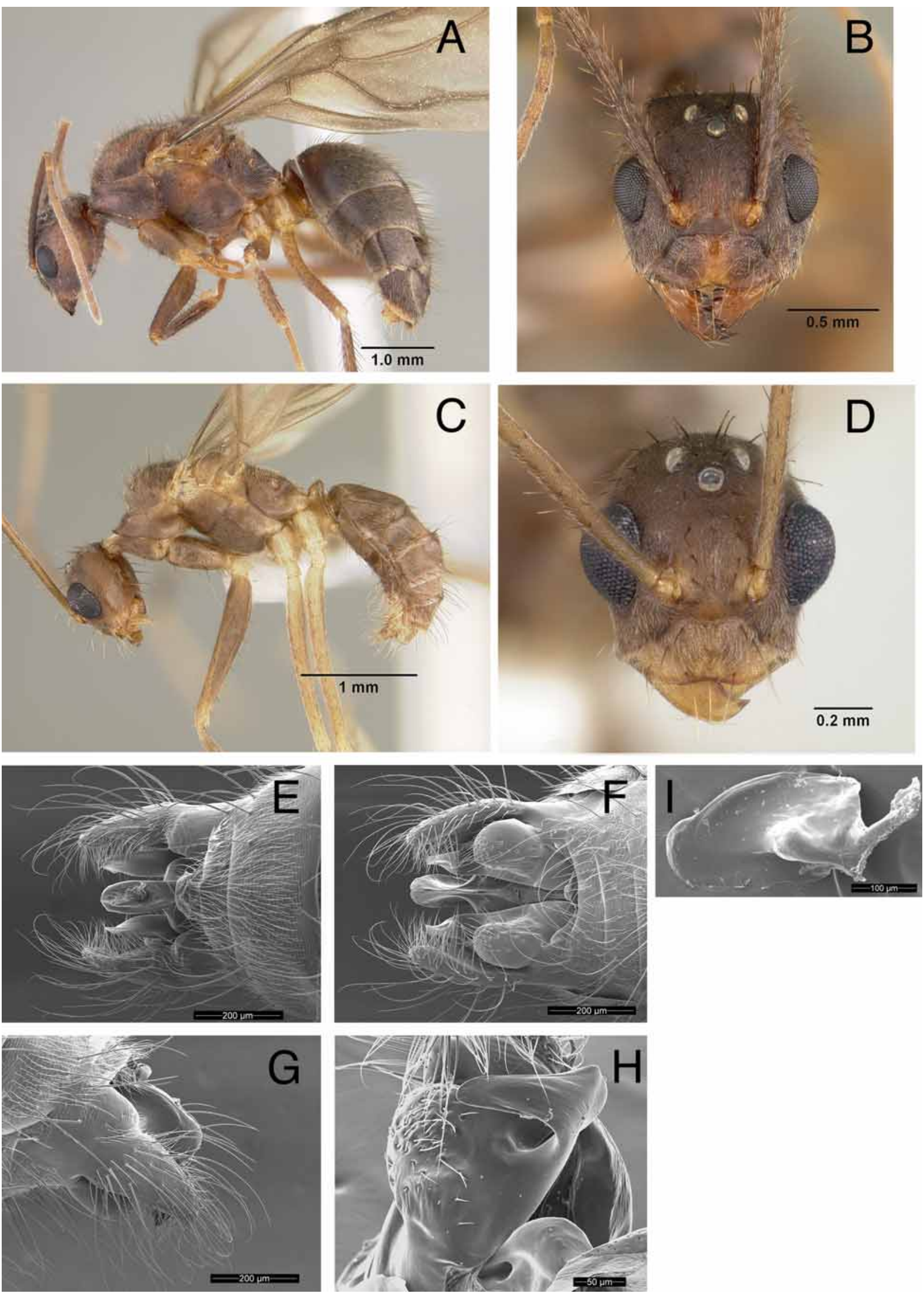

FIGURE 9A-I. E. procera queen and male. A) queen in lateral view; B) queen head in full-frontal view; C) male in lateral view; D) male head in full-frontal view; E-I male genitalia: E) dorsal view; F) ventral view; G) lateral view; H) volsellar lobe; I) penis valve. Queen and male are both from South Thailand (SYPC) 
Discussion: This is the only known polymorphic Euprenolepis species. Majors of E. procera superficially resemble Pseudolasius, but can be separated from that genus by the characters listed under the genus diagnosis section. This species possesses several unique characters other than worker polymorphism. $E$. procera has especially long scapes, although not as long as in E. negrosensis. The eyes of E. procera are more forward toward the midline and lower in the head than observed in other species. The medially emarginated clypeus is most pronounced in E. procera. It is by far the darkest colored species and possesses the thickest, most distinct rugoreticulae covering the body.

\section{Euprenolepis thrix, sp. nov.}

(Figures 10A-D)

Holotype worker, MALAYSIA: Borneo, Kinabalu Nat. Park, Poring Hot Spring, East Ridge, 800 m, 1995 (C. Brühl) (USNM); 3 paratype workers, same locality as holotype (ANIC; USNM).

Worker. Measurements ( $\mathrm{n}=3$ ): TL: 3.35-4.18; HW: 0.97-1.11; HL: 0.91-1.04; SL: 1.18-1.23; WL: 1.3-1.42; GL: 1.14-1.72. Indices: CI: 104-107; SI: 110-122.

Head brown, with lighter yellowish-brown mandibles and funiculi; head about as long as broad. Cuticular surface shiny and smooth, with scattered erect setae and sparse pubescence that is thickest in area under the eyes. Posterior margin complete. Scapes surpass posterior margin by about length of the first four funicular segments. Scapes with erect setae and a layer of pubescence, becoming denser distally. Mesosoma brown, smooth, and shiny, legs becoming lighter distally, especially tarsi, which are yellowish-brown. Mesosomal dorsum with scattered erect setae of varying lengths; cuticular surface without pubescence; legs with short erect setae. Pronotum rises at about $45^{\circ}$ toward mesonotum; propodeum dorsum rounded, dome-like; declivity steep. Petiole triangular with posterior face longer than anterior face; gaster brown, with scattered erect setae and a dense layer of pubescence; cuticular surface shiny, and weakly regureticulate.

Etymology: The species epithet is Greek for hair, in reference to the pubescence that covers the gaster of this species.

Discussion: This species is easily distinguished from other Euprenolepis species by the dense layer of pubescence on the gaster. Only two other species also have pubescence on the gaster: E. procera and E. zeta. Euprenolepis thrix is easily distinguishable from E. procera by the smooth surface of the cephalic and mesosomal cuticle. Euprenolepis thrix is distinguishable from E. zeta by denser gastral pubescence. Also, $E$. thrix and E. zeta have the head slightly broader than long (CI typically greater than 100), whereas other Euprenolepis have the head slightly longer than broad (CI typically less than 100). Shared body coloration, head shape, and the presence of pubescence on the gaster probably indicate that E. thrix and E. zeta are close relatives.

\section{Euprenolepis variegata, sp. nov.}

(Figures 11A-D)

Holotype worker, MALAYSIA: Borneo, Sabah, Danum Valley, West Trail P1, 250 m, ii.1999 (C. Brühl) (USNM); 2 paratype workers, same locality as holotype (ANIC; USNM); 1 paratype worker, MALAYSIA: Borneo, Sabah, Sepiok Forest Reserve, 60 m, ii.2000 (C. Brühl) (USNM).

Worker. Measurements (n=3): TL: 2.98-3.36; HW: 0.77-0.82; HL: 0.81-0.89; SL: 1.07-1.11; WL: 1.1-1.26; GL: 1-1.21. Indices: CI: 91-96; SI: 136-140

Head brown, with scapes and mandibles lighter and funiculi much lighter becoming brownish-yellow; head about as long as broad. Cuticular surface shiny and weakly rugoreticulate, with scattered erect setae, with only small areas of pubescence along clypeal margin. Scapes with scattered pubescence and erect setae; pubescence more abundant distally. Mesosoma light brown, shiny, with legs slightly lighter. Scattered erect 

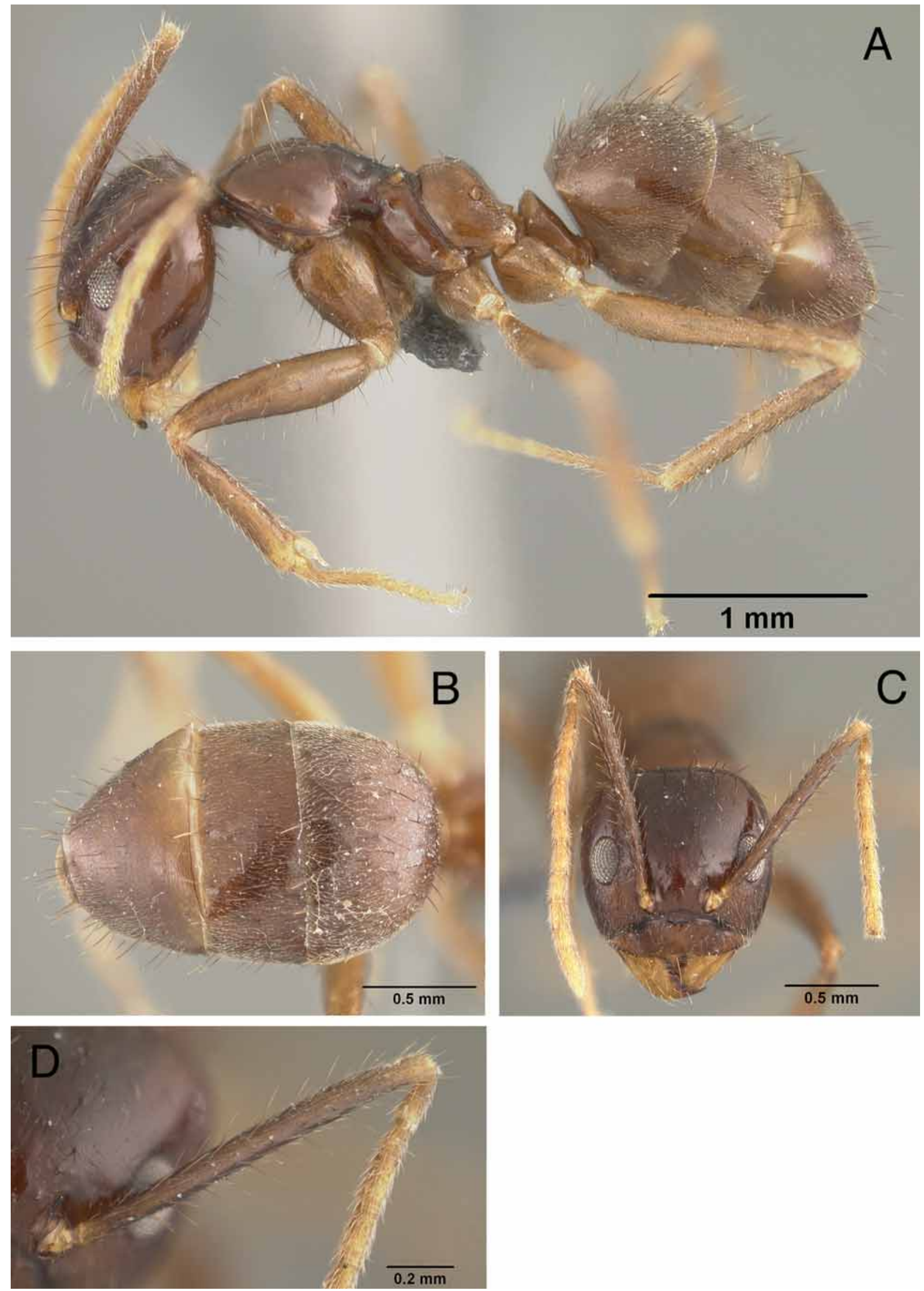

FIGURE 10A-D. E. thrix worker. A) lateral view; B) gaster in dorsal view; C) head in full-frontal view; D) scape. Holotype, Malaysia, Borneo (USNM). 

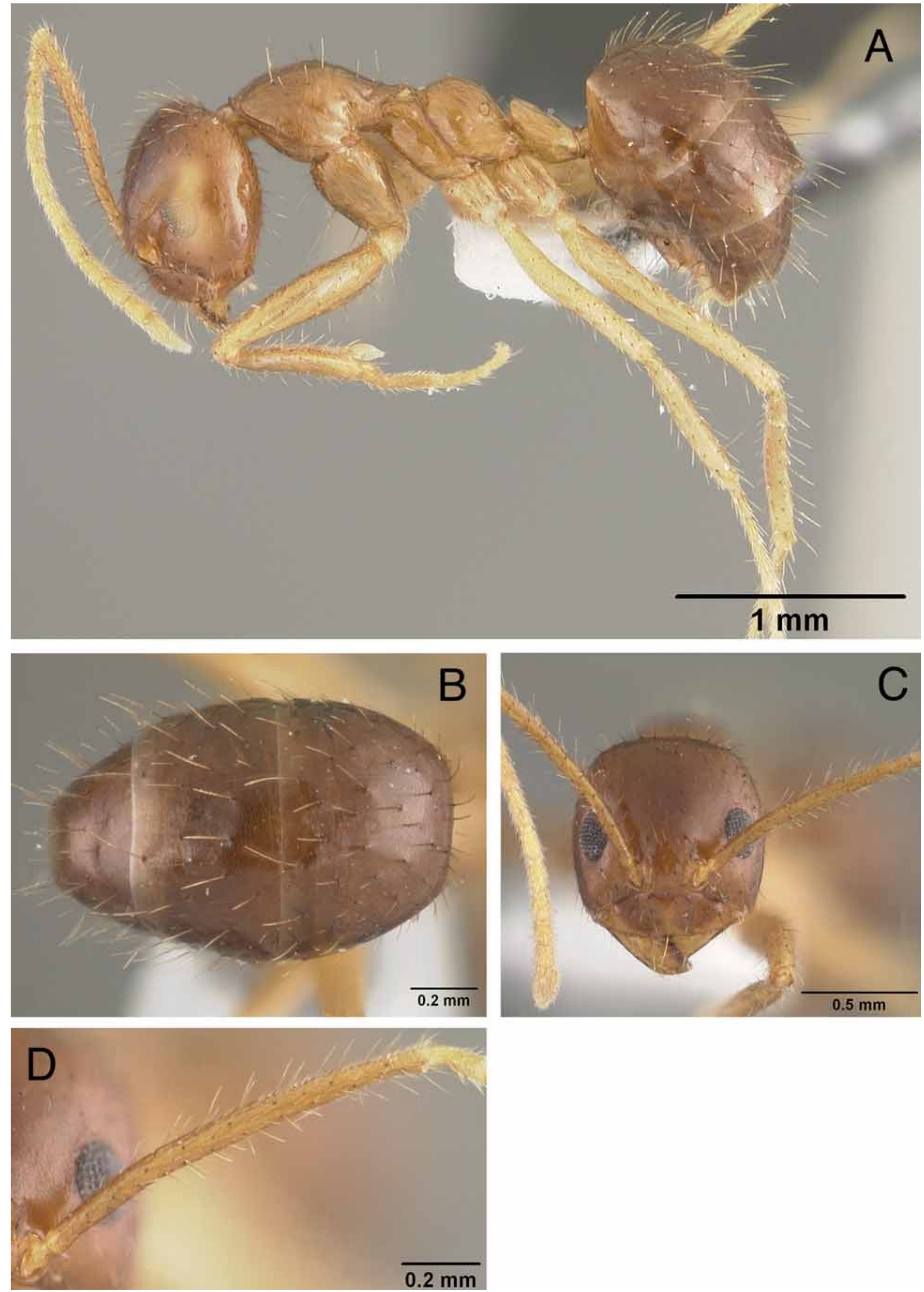

FIGURE 11A-D. E. variegata worker. A) lateral view; B) gaster in dorsal view; C) head in full-frontal view; D) scape. Holotype, Malaysia, Borneo (USNM) 
setae of varying lengths concentrated on posterior pronotum and anterior mesonotum. Pronotum rises at about $45^{\circ}$ toward mesonotum; propodeum dorsum rounded, dome-like; declivity short, but steep. Petiole triangular, inclined forward, with posterior face longer than anterior face; gaster darker brown than mesosoma, with erect setae and no pubescence; cuticular surface shiny and weakly rugoreticulate.

Etymology: The species epithet is Latin for different, in reference to its separation from E. wittei.

Discussion: E. variegata workers are most likely to be confused with E. wittei. The two species can be separated based on the fact that E. variegata is lighter in color, has scattered pubescence on the scapes, becoming dense distally, and longer erect setae on the gaster than those of E. wittei.

\section{Euprenolepis wittei, sp. nov.}

(Figures 12A-D [worker]; 13A-I [queen and male])

Holotype worker, MALAYSIA: West Malaysia, Ulu Gombak Field Station, 319'N, $101^{\circ} 54^{\prime}$ E, nest series, 10.iv.2006 (V. Witte) (USNM); 5 paratype workers, same locality as holotype (ANIC; USNM).

Worker. Measurements (n=3): TL: 3.13-3.61; HW: 0.80-0.86; HL: 0.82-0.89; SL: 1.06-1.12; WL: 1.1-1.18; GL: 1.21-1.54. Indices: CI: 96-98; SI: 130-132

Generally matching the description of E. variegata with the following differences: 1) Overall darker brown in color, especially the head and gaster which are darker than mesosoma, 2) in profile, pronotal margin more rounded dorsoanteriorly, 3) scapes with a dense layer of pubescence distally, and 4) erect setae on gaster shorter than those of $E$. variegata.

Queen. Measurements (n=1): TL: 6.74; HW: 1.14; HL: 1.22; SL: 1.4; WL: 2.26; GL: 3.26. Indices: CI: 93; SI: 123.

As in worker, with modifications expected for caste and the following differences: Head, pronotum+mesonotum, and gaster darker brown with lighter yellowish-brown funiculi, legs, and propodeum+petiole. Entire body covered in a dense layer of pubescence; short erect setae cover head, mesosoma notum, legs and gaster.

Male. Measurements (n=2): TL: 3.32-3.37; HW: 0.59-0.6; HL: 0.73; SL: 1.06-1.18; WL: 1.41-1.42; GL: 1.17-1.23. Indices: CI: 82-83; SI: 176-199.

Overall color brown to brownish-yellow, lighter brown to yellow on legs and funiculi; head longer than broad. Cuticular surface shiny, covered in a dense layer of pubescence. Scapes long, surpassing posterior margin by about length of first four funicular segments; scapes with scattered erect setae and a dense layer of pubescence. Clypeus broad, with anterior margin emarginated. Mandible with a basal angle and a distinct apical tooth that curves inward toward midline of body. Mesosoma enlarged to accommodate flight muscles; covered in a layer of pubescence, with erect setae present dorsally and along legs. Pronotum small and collarlike; mesonotum flat dorsally with scattered erect setae; propodeum indistinct from remainder of mesonotum, but declivity steep. Petiole triangular, inclined forward, with posterior face longer than anterior face. Gaster with a dense layer of pubescence and many erect setae; terminalia especially setose. Parameres roughly triangular, turning slightly inward toward midline of body posteriorly; long setae extend off of parameres. Cuspi small and tubular, reaching digiti dorsally; digiti anvil-shaped, ventrally directed; digiti visible in lateral view. Volsellar lobes flat and indistinct. Penis valves with apodeme projecting dorsally; in lateral view the valves extend dorsally.

Etymology: The species epithet is given to honor Volker Witte for his insightful contributions to Euprenolepis natural history.

Additional material examined: INDONESIA: West Sumatra, Ulu Gadut near Padang, 18.ii.2007, under stone in soil (S. Yamane); THAILAND: S. Thammarat Prov., Papra Station, Khao Nan Nat. Park, Nakhou.

Discussion: Workers of this species are most likely to be confused with E. variegata, but can be separated based on the characters listed above. This appears to be a monomorphic species, for V. Witte (pers. comm.) has collected large nest series of this species and major workers have yet to be discovered. 

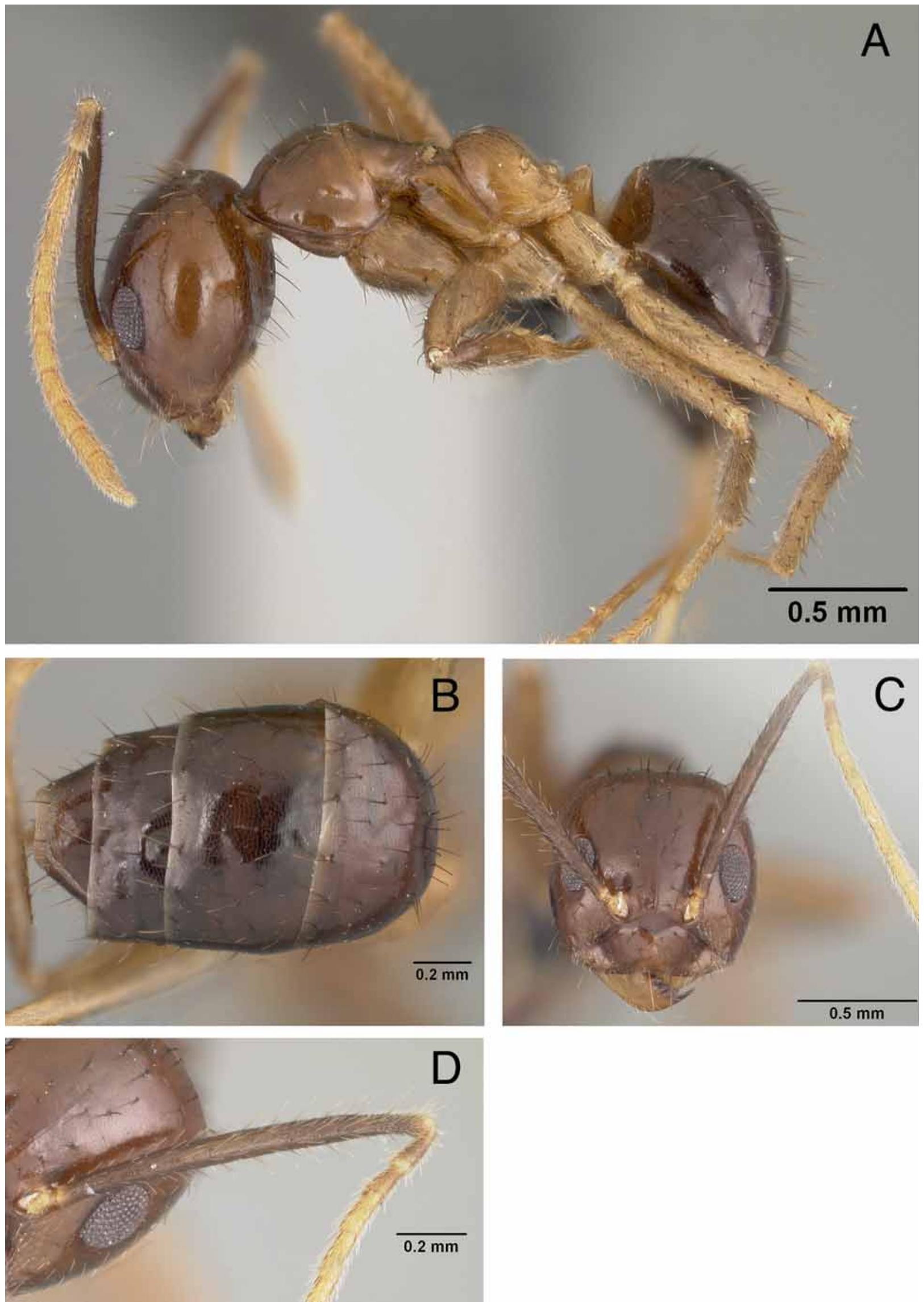

FIGURE 12A-D. E. wittei worker. A) lateral view; B) gaster in dorsal view; C) head in full-frontal view; D) scape. Holotype, Malaysia,West Malaysia (USNM) 

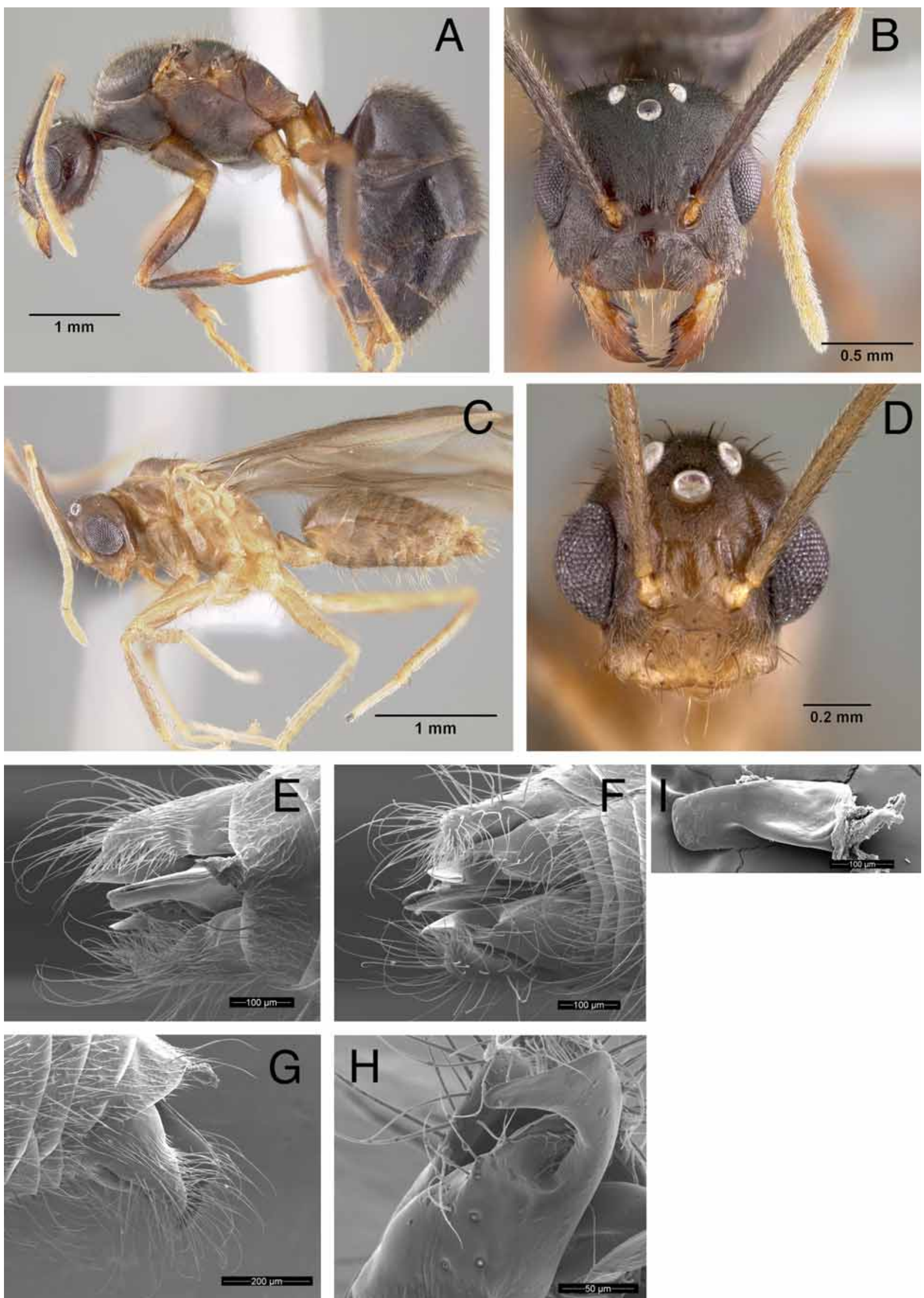

FIGURE 13A-I. E. wittei queen and male. A) queen in lateral view; B) queen head in full-frontal view; C) male in lateral view; D) male head in full-frontal view; E-I male genitalia: E) dorsal view; F) ventral view; G) lateral view; H) volsellar lobe; I) penis valve. Queen and male are both from Malaysia,West Malaysia (USNM) 

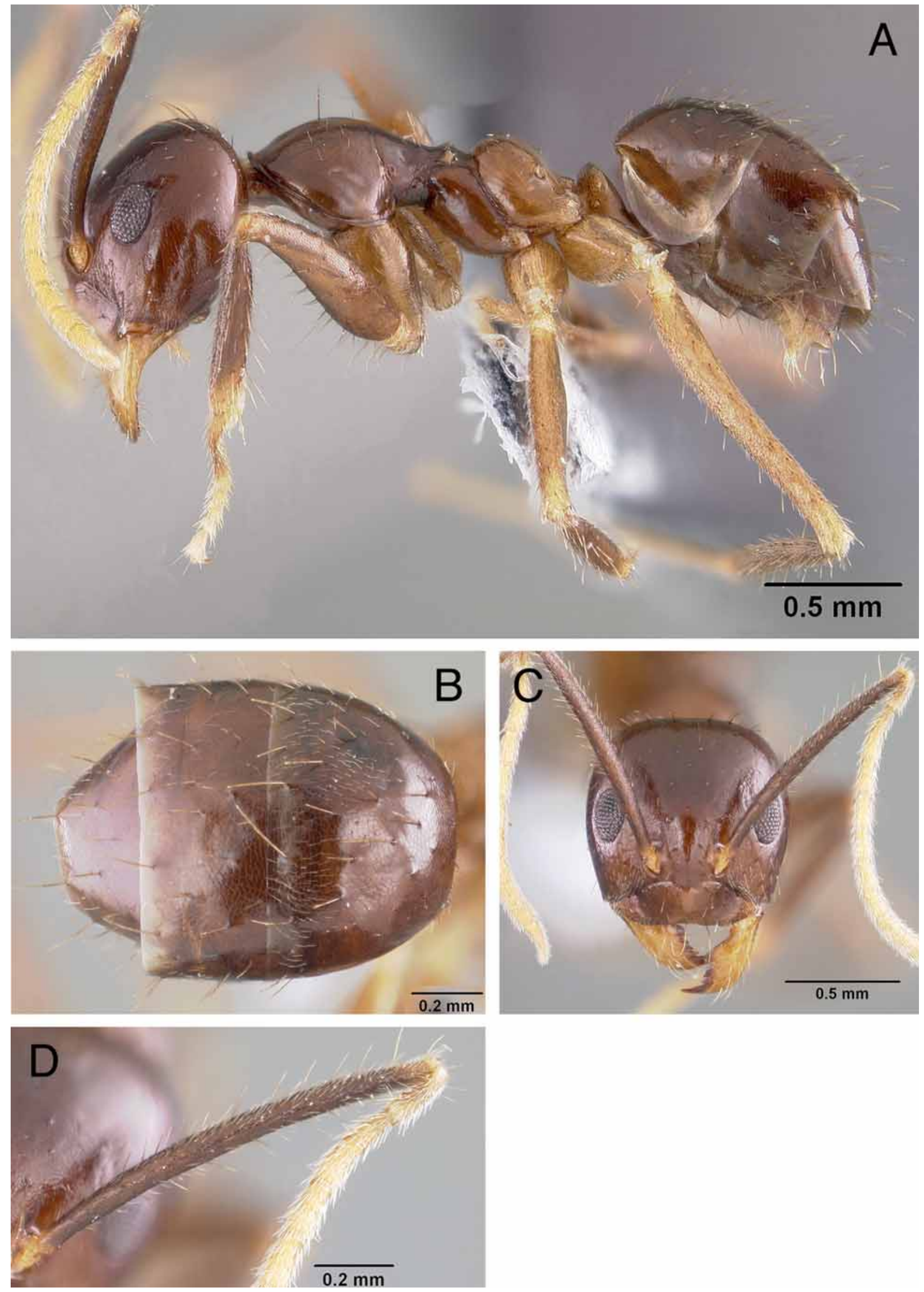

FIGURE 14A-D. E. zeta worker. A) lateral view; B) gaster in dorsal view; C) head in full-frontal view; D) scape. Holotype, Malaysia, Borneo (USNM) 
Holotype worker, MALAYSIA: Borneo, Sabah, Sepilok Forest Reserve, 60 m, ii.1999 (C. Brühl) (USNM); 1 paratype worker, same locality as holotype (ANIC).

Worker. Measurements (n=3): TL: 2.69-3.22; HW: 0.77-0.86; HL: 0.76-0.86; SL: 0.98-1.03; WL: 1.02-1.16; GL: 0.86-1.2. Indices: CI: 99-104; SI: 116-130

Head brown, with lighter yellowish-brown mandibles and funiculi; head about as long as broad. Cuticular surface shiny and smooth, with scattered erect setae and sparse pubescence that is thickest in area under the eyes. Posterior margin complete. Scapes surpass posterior margin by about length of the first four funicular segments. Scapes with erect setae and a layer of pubescence, becoming denser distally. Mesosoma brown, smooth and shiny, legs lighter, especially tarsi, which become yellowish-brown. Mesosomal dorsum with scattered erect setae of varying lengths; cuticular surface without pubescence. Pronotum rises at about $45^{\circ}$ toward mesonotum; propodeum dorsum rounded, dome-like; declivity short, but steep. Petiole triangular with posterior face longer than anterior face; gaster brown, with scattered erect setae and a sparse layer of pubscence; cuticular surface shiny and weakly reguoreticulate.

Etymology: The species epithet is Greek. Zeta is the sixth letter of the Greek alphabet, and this was the sixth and final new species discovered during the course of this revision.

Additional material examined: MALAYSIA: Borneo, Sabah, Danum Valley, West Trail P1, 250 m, 17.viii.1997 (C. Brühl); Borneo; Kinabalu Nat. Park; Poring Hot Spring, East Ridge; 560 m (C. Brühl).

Discussion: This species is most likely to be confused with E. thrix, but E. zeta has far less pubescence on the gaster. As in E. thrix, E. zeta does have the head wider than long, an unusual trait among Euprenolepis species. Based on overall morphological similarity, including the head shape and presence of pubescence on the gaster, it is likely that E. thrix and E. zeta are close relatives.

\section{Acknowledgments}

I thank Gary Alpert, Barry Bolton, Daniel Burckhardt, Stefan Cover, Katsuyuki Eguchi, Frank Koch, Bernhard Merz, Roberto Poggi, Christine Taylor, Volker Witte, and Seiki Yamane for arranging specimen loans. I also thank Katsuyuki Eguchi, Jack Longino and Steve Shattuck for thoughtful comments on the manuscript. Katsuyuki Eguchi kindly provided me with the males of E. negrosensis. This research was supported by the National Science Foundation under grant no. DEB-0743542 awarded to JSL. Support was also provided by the Towson University Office of University Research Services and the TU Academy of Scholars.

\section{References}

Agosti, D. (1991) Revision of the oriental ant genus Cladomyrma, with an outline of the higher classification of the Formicinae (Hymenoptera: Formicidae). Systematic Entomology, 16, 293-310.

Baltazar, C.R. (1966) A catalogue of Philippine Hymenoptera (with a bibliography, 1758-1963). Pacific Insects Monograph, 8, 1-488.

Bolton, B. (1994) Identification guide to the ant genera of the world. Harvard University Press, Cambridge, Massachusetts. 222 pp.

Bolton, B. (1995) A new general catalogue of the ants of the world. Harvard University Press, Cambridge, Massachusetts. 504 pp.

Bolton, B. (2003) Synopsis and Classification of Formicidae. Memoirs of the American Entomological Institute, 71, 1370.

Bolton, B., Alpert, G., Ward, P.S. \& Naskrecki, P. (2006) Bolton's catalogue of ants of the world: 1758-2005 [CD-ROM]. Havard University Press, Cambridge, Massachusetts. 
Brown, W.L., Jr. (1953) Characters and synonymies among the genera of ants. Part II. Breviora, 18, 1-8.

Chapman, J.W. \& Capco, S.R. (1951) Check list of the ants (Hymenoptera: Formicidae) of Asia. Monographs of the Institute of Science and Technology. Manila, 1, 1-327.

Dlussky, G.M. \& Fedoseeva, E.B. (1988) Origin and early stages of evolution in ants. Pp. 70-144 in: Ponomarenko, A. G. (ed.) Cretaceous biocenotic crisis and insect evolution. Moskva: Nauka, $232 \mathrm{pp}$.

Donisthorpe, H. (1941) New ants from Waigeu Island, New Guinea, and the Solomons. Entomologist, 74, 36-42.

Donisthorpe, H. (1943) A list of the type-species of the genera and subgenera of the Formicidae. [part]. Annals and Magazine of Natural History, 11(10), 617-688.

Emery, C. (1900) Formiche raccolte da Elio Modigliani in Sumatra, Engano e Mentawei. [part]. Annali del Museo Civico di Storia Naturale di Genova, 40[=(2(20)], 689-720.

Emery, C. (1906) Note sur Prenolepis vividula Nyl. et sur la classification des espèces du genre Prenolepis. Annales de la Société Entomologique de Belgique, 50, 130-134.

Emery, C. (1925) Hymenoptera. Fam. Formicidae. Subfam. Formicinae. Genera Insectorum, 183, 1-302.

Forel, A. (1910) Formicides australiens reçus de MM. Froggatt et Rowland Turner. Revue Suisse de Zoologie, 18, 1-94.

Forel, A. (1913) Wissenschaftliche Ergebnisse einer Forschungsreise nach Ostindien ausgeführt im Auftrage der Kgl. Preuss. Akademie der Wissenschaften zu Berlin von H. v. Buttel-Reepen. II. Ameisen aus Sumatra, Java, Malacca und Ceylon. Gesammelt von Herrn Prof. Dr. v. Zoologische Jahrbücher. Abteilung für Systematik, Geographie und Biologie der Tiere, 36, 1-148.

Forel, A. (1917) Cadre synoptique actuel de la faune universelle des fourmis. Bulletin de la Socit vaudoise des sciences naturelles, 51, 229-253.

Hölldobler, B. \& Wilson, E.O. (1990) The ants. Harvard University Press, Cambridge, Massachusetts. 732 pp.

Mann, W.M. (1919) The ants of the British Solomon Islands. Bulletin of the Museum of Comparative Zoology, 63, $273-391$.

Viehmeyer, H. (1914[1913]) Neue und unvollständig bekannte Ameisen der alten Welt. Archivum Zoologicum, (A)79(12), 24-60.

Ward, P.S. (2001) Taxonomy, phylogeny and biogeography of the ant genus Tetraponera (Hymenoptera:Formicidae) in the Oriental and Australian regions. Invertebrate Taxonomy, 15, 589-665.

Wheeler, G.C., Wheeler, J. (1985) A simplified conspectus of the Formicidae. Transactions of the American Entomological Society, 111, 255-264.

Wheeler, W.M. (1910) Ants: their structure, development and behavior. Columbia University Press, NewYork, New York. 663 pp.

Wheeler, W.M. (1922) Ants of the American Museum Congo expedition. A contribution to the myrmecology of Africa. VII. Keys to the genera and subgenera of ants. Bulletin of the American Museum of Natural History, 45, 631-710.

Wheeler, W.M. (1930) Two new genera of ants from Australia and the Philippines. Psyche (Cambridge), $37,41-47$.

Witte,V. \& Maschwitz, U. (2008) Mushroom harvesting ants in the tropical rain forest. Naturwissenschaften, 95(11), 1049-54. 